\title{
Protestantismo e Educação Social: uma análise histórica de iniciativas promovidas pela mais antiga instituição educacional presbiteriana do Brasil
}

\author{
Lucas Pereira Rezende ${ }^{1}$ \\ Marcel Mendes ${ }^{2}$
}

\begin{abstract}
Resumo: O presente artigo toma iniciativas educacionais do presbiterianismo no Brasil como objeto de uma investigação histórica com foco no terreno social, promovendo um debate sobre o alcance social que os valores educacionais calvinistas podem ter na sociedade na qual se inserem, especialmente discutidos a luz de conceitos contemporâneos ligados à área da Educação Social. É apresentada uma contextualização das iniciativas que são objeto de estudo, e que são ligadas à mais antiga instituição educacional de origem protestante do país, o Colégio Internacional, que devido a uma mudança geográfica de localização passou a se chamar Instituto Evangélico de Lavras, atualmente Instituto Presbiteriano Gammon, sendo que com o desmembramento da Escola Superior de Agricultura em 1963, gerou posteriormente a Universidade Federal de Lavras. $\mathrm{O}$ recorte temporal da pesquisa se liga às décadas iniciais de inserção do presbiterianismo com suas iniciativas educacionais no interior de Minas Gerais;
\end{abstract}

Palavras-chave: Educação Social; Pedagogia Protestante; Instituto Presbiteriano Gammon

\section{Protestantism and Social Education: a historical analysis of initiatives promoted by the oldest Presbyterian educational institution in Brazil}

\begin{abstract}
This article takes educational initiatives from Presbyterianism in Brazil as the object of a historical investigation focusing on the social field, promoting a debate on the social scope that Calvinist educational values can have in the society in which they operate, especially discussed in the light of contemporary concepts linked to the area of Social Education. It presents a contextualization of the initiatives that are the object of study, and that are linked to the oldest educational institution of Protestant origin in the country, the International College, which, due to a geographic change in location, was renamed Instituto Evangélico de Lavras, now Institute Presbyterian Gammon, with the dismemberment of the Superior School of Agriculture in 1963, later generated the University Federal of Lavras. The time frame of the research is linked to the initial

\footnotetext{
${ }^{1}$ Mestre em Educação, Arte e História da Cultura pela Universidade Presbiteriana Mackenzie. Professor da Faculdade Teológica Vida em São Paulo. São Paulo, Brasil. E-mail: lucaspereirarezende@ hotmail.com ORCID: https://orcid.org/0000-0002-4849-1609.

2 Doutor em História Social pela Universidade de São Paulo. Professor do Programa de Pós-Graduação em Educação, Arte e história da Cultura da Universidade Presbiteriana Mackenzie em São Paulo. São Paulo, Brasil. E-mail: marcel.mendes@ mackenzie.br ORCID: https://orcid.org/0000-0003-3878-5221.
} 
decades of insertion of Presbyterianism with its educational initiatives in the interior of Minas Gerais.

Keywords: Social Education; Protestant Pedagogy; Institute Presbyterian Gammon

\section{Protestantismo y Educación Social: un análisis histórico de las iniciativas impulsadas por la institución educativa presbiteriana más antigua de Brasil}

Resumen: Este artículo toma iniciativas educativas del presbiterianismo en Brasil como objeto de una investigación histórica con enfoque en el campo social, promoviendo un debate sobre el alcance social que los valores educativos calvinistas pueden tener en la sociedad en la que operan, especialmente discutido en a la luz de conceptos contemporáneos vinculados al área de Educación Social. Presenta una contextualización de las iniciativas que son objeto de estudio, y que están vinculadas a la institución educativa de origen protestante más antigua del país, el International College, que por un cambio geográfico de ubicación pasó a denominarse Instituto Evangélico de Lavras. , hoy Instituto Evangélico de Lavras, actual Instituto Evangélico de Lavras Presbyterian Gammon, con el desmembramiento de la Escuela Superior de Agricultura en 1963, posteriormente generó la Universidad Federal de Lavras. El marco temporal de la investigación está vinculado a las décadas iniciales de inserción del presbiterianismo con sus iniciativas educativas en el interior de Minas Gerais;

Palabras clave: Educación Social; Pedagogía protestante; Instituto Presbiteriano Gammon

\section{Considerações Iniciais}

Em 1869 foram iniciados os trabalhos da primeira escola de orientação protestante do Brasil, o Colégio Internacional, que foi fundado na cidade de Campinas pelos missionários americanos George Nash Morton (1841-1925) e Edward Lane (1835-1892) que haviam chegado ao Brasil naquele mesmo ano.

Depois de funcionar cerca de 20 anos na cidade paulista, em 1892 sob a direção do missionário Samuel Rhea Gammon (1865-1928), a instituição foi transferida para a cidade mineira de Lavras. A transferência foi devida á sucessivas epidemias de febre amarela que sobrevieram à cidade de Campinas nas últimas décadas do século XIX, causando a morte de milhares de pessoas inclusive missionários norte-americanos. Ao ser instalada na cidade mineira, a instituição recebeu o nome de Instituto Evangélico , e foi responsável pela implantação do ensino primário e ginasial, com posterior fundação da Escola Agrícola de Lavras, que no decorrer dos anos se consolidou como importante promotora do ensino superior agrícola no país, mudando seu nome para Escola Superior de Agricultura de Lavras (ESAL) em 1938, nome que manteve até 1994, quando foi 
transformada em Universidade Federal de Lavras pela lei 8.956/94, sendo que neste interregno houve sua federalização, mais precisamente no ano de 1963.

Para além dos benefícios gerais para a educação no Brasil advindos do trabalho realizado por estas instituições de ensino, uma investigação histórica das atividades educacionais desenvolvidas por estes missionários permite a constatação de iniciativas que se relacionam com uma área de estudos que vem alcançando proeminência no contexto das abordagens acadêmicas, que se trata da Educação Social.

A análise que está documentada no presente artigo se desenvolveu a partir da perspectiva do pesquisador e educador Moacir Gadotti (2013, p. 9), que ao pontuar sobre iniciativas educacionais desenvolvidas no Brasil no decorrer da história, reconhece que "não podemos afirmar que a educação social seja propriamente uma novidade hoje no Brasil”, pois conforme pontua o autor:

[...] o que é novidade sim, é o seu desenvolvimento recente e o crescente debate em torno da pedagogia social. Talvez a novidade esteja mais no interesse acadêmico em torno desta questão e a consequente estruturação da educação social como área de produção acadêmica e de formação profissional (GADOTTI, 2013, p.9).

Tal afirmação pauta a proposta deste sinótico ensaio, que é desvelar os valores do protestantismo de missão que chegado ao Brasil na segunda metade do século XIX, mais especificamente o de linha calvinista, demonstrou sua expressão também nas linhas de uma pedagogia social, com implicações diretas nas comunidades onde o trabalho missionário se desenvolveu.

Conforme aponta o historiador Reinhart Koselleck (2006, p. 267), "nenhum relato de coisas passadas pode incluir tudo o que então existiu ou ocorreu”, e de fato, não é pretensão deste artigo esgotar qualquer tipo de abordagem, mas apenas contribuir no âmbito da pesquisa acadêmica em relação ao contexto em que se desenvolve as iniciativas educacionais em questão, relacionando-as aos conceitos acadêmicos contemporâneos que envolvem a Educação Social, encetando assim o debate analítico orientado pelos conceitos da pedagogia social, e viabilizando mais um espectro de análise do trabalho destes educadores que atuaram no país há mais de 100 anos atrás, em uma realidade de profundas vulnerabilidades sociais, que ao invés de ignoradas, foram enfrentadas em uma expressão prática de educação social que gerou transformações profundas em contextos e histórias pessoais e coletivas. 


\section{A inserção do calvinismo no Brasil}

Sabe-se que primeira tentativa de inserção de pregação calvinista no Brasil aconteceu muitos anos antes da chegada dos missionários americanos. Ainda no século da Reforma, calvinistas vítimas de perseguição religiosa na França vieram buscar refúgio nas terras do Brasil. O convite foi feito pelo almirante francês Nicolas Durand Villegaignon, e o ano de chegada destes huguenotes ${ }^{3}$ foi 1557 . No entanto, aqui chegando, uma séria desavença de ordem doutrinária religiosa decorreu na fuga dos huguenotes de volta para a França, com exceção de cinco deles, que devido à carência de recursos e meios para a viagem de volta permaneceram no Brasil e se tornaram vítimas de perseguição religiosa, o mesmo motivo que os fizeram sair da Europa.

A tomada de conhecimento destes fatos na Europa, somada ao êxito da inquisição em Portugal e na colônia, contribuiu para que a pregação protestante estivesse ausente no Brasil desde então, tendo como única exceção a tentativa de colonização holandesa no Nordeste entre 1630 e 1654, liderada por Nassau (RIBEIRO, 1937).

No entanto, de forma prática, os mais variados historiógrafos destes fatos não têm apontado qualquer herança mais significativa destas presenças protestantes no Brasil até o início do movimento missionário americano, que se faz presente com o contexto de abertura que se inicia em 1808 com a vinda da família real para o Brasil, promovendo melhorias políticas, sociais e religiosas no mais curto prazo, desde a Carta Régia que permite a abertura dos portos brasileiros para todas as nações amigas com a desinente circulação de estrangeiros protestantes no território brasileiro, como a publicação em 1810, do "Tratado de Aliança e Amizade" entre a coroa portuguesa e a Inglaterra, que permitia aos ingleses o culto e até mesmo a utilização de espaços para tais, desde que não possuíssem as características de templo, ou que tivessem sinos. Neste interregno também são designados cemitérios para o sepultamento dos praticantes do culto da reforma. No entanto, aos praticantes do protestantismo era proibido fazer prosélito e se algum inglês desejasse se naturalizar português ou brasileiro, deveria tornar-se católico. Daí o fato de que quando se proclamou a independência do Brasil em 1822, não havia igreja protestante no país, não havia culto protestante na língua do país, e não há registro de existir sequer um brasileiro protestante (RIBEIRO, 1937).

\footnotetext{
3 “Nome de origem obscura que se dava aos protestantes na França.” (González, 2011, p. 100)
} 
É na elaboração da constituinte nos anos seguintes, 1823 e 1824, que acontece significativo debate sobre a questão religiosa. A influência de economistas e políticos que defendiam a ideia de progresso inglesa e liberdade francesa é notória. Oliveira (2014) ressalta que ao longo do século XIX as condições sociais, econômicas e culturais se modificam drasticamente, principalmente influenciadas por três eventos de impacto mundial: a Independência dos Estados Unidos, a Revolução Francesa e a Revolução Industrial. Estes eventos acabam por alterar os modelos políticos e sociais. A luta anticolonial, a defesa de um governo representativo com bases liberais, a separação entre o Estado e a Igreja, são princípios e vivências já presentes na mentalidade política, econômica e social deste período. Tais ideais influenciam a constituinte e de forma indireta favorecem a inserção do protestantismo e seus princípios no Brasil. No documento de 1824 percebem-se liberdades e restrições, mas já se reconhece cidadãos brasileiros independentes de sua religião.

É neste contexto e momento histórico que se iniciam nas igrejas norte-americanas os movimentos de conscientização missionária em relação ao Brasil, e é na segunda metade do século XIX que tais movimento se efetivaram de maneira prática, com a chegada dos primeiros missionários norte-americanos ao Brasil, dentre eles o primeiro presbiteriano, Ashbel Green Simonton (1833-1867), que aqui desembarcou em 1859.

\section{A tradição educacional calvinista e as dificuldades do Brasil com a educação}

Ao tratar sobre a influência de Calvino na educação, Wilson Castro Ferreira (1990) utiliza um exemplo prático muito interessante para se perceber como a questão educacional está intimamente ligada ao calvinismo. Tomando como exemplo uma comunidade protestante rural, o autor fala sobre compromissos que pais protestantes assumem no momento do batismo de seus filhos, de alfabetizá-los, para que quando crescidos possam ler as Escrituras Sagradas. Tal promessa assumida pelos pais diante de toda igreja, como neste caso real citado pelo autor, tornou-se o meio viabilizador para que a referida comunidade que tinha no seu seio uma igreja reformada, também tivesse uma escola em pouco tempo, diferentemente da grande maioria de comunidades rurais da mesma região, que como àquela eram relegadas ao esquecimento pelos poderes, tanto municipais, como estaduais.

O princípio de Calvino era exatamente esse, ele tinha a instrução como principal ferramenta para o desenvolvimento espiritual dos indivíduos. A leitura das suas obras 
permite perceber que João Calvino "acreditava na religião inteligente, fruto do intelecto, tão bem como das emoções. Dizia ele que um dos mais tenazes inimigos da verdadeira religião é a ignorância” (TAYLOR apud FERREIRA, 1990, p.183). Outros autores afirmam que "Calvino desenvolveu uma perspectiva de vida que reconhecia os valores da razão e da inteligência humana". Em pesquisa biográfica sobre o autor, Ferreira (1990) levanta inúmeras citações de variados autores que convergem nessa perspectiva comum, de que a educação não somente ocupa o âmago do pensamento do reformador de Genebra, como também é elemento protagonista em seu grande sonho para a sociedade de seu tempo, que tinha como elemento último e central a glorificação do criador.

Permeado por tais princípios é que Simonton desembarcou no Brasil, e se viu diante de um crasso analfabetismo espalhado por todo território nacional. Em relatório pastoral apresentado ao concílio da igreja até então existente, o Presbitério do Rio de Janeiro, Simonton afirma:

Outro meio indispensável para assegurar o futuro da igreja evangélica no Brasil é o estabelecimento de escolas para os filhos de seus membros [...] Mas é necessário não cedermos a nenhum obstáculo [...] $\mathrm{O}$ Evangelho dá estímulo a todas as faculdades do homem e o leva a fazer os maiores esforços para avançar na senda do progresso (SIMONTON, 1867 apud HACK, p. 59).

A contextualização histórica apresentada visa demonstrar que a inserção do calvinismo no Brasil envolveu naturalmente uma preocupação com a situação da educação brasileira, e nesse sentido se encaixou bem com as dificuldades do país no terreno social. De acordo com o pesquisador Osvaldo Hack (2000, p.26), o próprio Imperador D. Pedro II via na imigração protestante uma alternativa nesse "terreno social", devido à situação crítica do país na área educacional, de crasso analfabetismo. "A presença de novos missionários seria mais uma oportunidade de serviço para o desenvolvimento do Brasil, principalmente na área educacional.”

De fato, a argumentação contemporânea da Educação Social é exatamente a perspectiva precípua de que "toda a educação é, ou deve ser, social, já que quando falamos de educação não podemos prescindir da sociedade, da comunidade e do contexto familiar, social e político onde vivemos" (GADOTTI, 2013, p. 9). Para Gadotti (2013, p. 9), tal compreensão é necessária exatamente "para não restringir o campo de atuação do educador social [grifo meu]". 
À luz de tais considerações pontua-se que tratar de educação no Brasil no contexto da sociedade brasileira da segunda metade do século XIX, envolvia naturalmente atuar no campo social, uma vez que o analfabetismo era um grande impasse para o desenvolvimento da jovem república brasileira.

\section{A realidade educacional do Brasil e a sensibilidade dos missionários protestantes}

Na obra do missionário J. F. Dagama, que trabalhou no interior de São Paulo no final do século XIX, é encontrada uma narrativa de fatos reveladores da condição educacional do Brasil naquele período. Em um desses relatos, o referido autor fala sobre sua experiência vivida em vilas do interior da província de São Paulo:

Em minhas viagens de pregação pelo interior, encontrei muitos lugares
onde vastos trechos chamados Distritos, em alguns dos quais ninguém
sabia ler [...] Em um desses Distritos com 16 milhas por 10, nem sequer
uma pessoa sabia ler. Depois do culto, quando eu estava de saída, um
velho perguntou-me: E como vamos fazer para santificar o domingo?
Nenhum de nós sabe ler; não sabemos cantar; ainda não sabemos orar.
Fazer o quê? (DAGAMA, 1882, apud p. 58)

Não se deve ter em mente outra ideia relativa às condições da velha cidade de Lavras do Funil $M G$, na ocasião da chegada dos missionários americanos que também se deu no final do século XIX. Em descrição sobre a cidade nesse período, que pode ser encontrada na biografia escrita por Clara Gammon, a situação de precariedade do município é notória, e simples pesquisa permitirá descobrir que o mesmo acontecia em relação à situação educacional, vale citar como exemplo o fato de que o primeiro grupo escolar só foi inaugurado no século XX, no dia 13 de maio de 1907, pelo famoso educador Firmino Costa. Nesse sentido, torna-se fácil presumir qual era a condição do lugar e da população em relação à carência de instrução.

Lavras era naquele tempo, uma velha cidade, datando dos dias coloniais e, como o seu nome indica, tinha sido cenário de grande mineração, na busca do ouro que enriquecia a coroa de Portugal. Pode-se dizer que havia uma rua, que se estendia em zigue-zague pela colina, cerca de quatro quilômetros, até terminar no Alto do Cruzeiro [...].

As ruas eram poeirentas ou lamacentas, conforme a estação, e ainda rasgadas pelas rodas dos pesados carros de boi. As casas em geral, eram de construção simples, mas sempre pintadas de cores varieagadas. $\mathrm{Na}$ praça central, grande e deserta, onde ser erguia a igreja matriz, havia um certo número de sobrados, onde vivia a elite. Essas casas, de estilo colonial, eram bem mobiliadas e adornadas com pinturas $e$ revestimento caprichoso, refletindo o luxo e a riqueza de dias 
prósperos. Nos arredores da cidade, porém, se amontoavam os casebres cobertos de capim, atestando a maior pobreza. Eram assim as cidades antigas do interior de Minas [grifo meu] [...]

Essa foi a cidade que o Dr Gammon escolheu para sua morada e centro de seu grande empreendimento. Ele iria acompanhar o seu progresso e contribuir para ele; iria partilhar das alegrias e tristezas do seu povo; iria tornar-se uma parte da própria vida dela (GAMMON, 2003, p. 58).

Mais do que informações, o relato de Clara Gammon transmite também uma percepção do que Émile Durkheim (2011, p.11) define como "fatos sociais", onde estão inclusos sistemas financeiros e costumes de uma sociedade, capazes de oferecer imposições aos indivíduos e padrões culturais, nos auferindo também através do relato, uma leitura da própria impressão que os missionários americanos tinham em relação ao contexto social em que se inseriam, de modo a lhes influenciar em relação aos projetos que seriam desenvolvidos. A percepção dos missionários em relação a uma marginalização dos pobres nos arredores da cidade, apresentada como uma realidade comum das cidades mineiras, não revelam um obstáculo, mas parece nesse relato, apontar para um desafio a ser enfrentado, talvez até mesmo um motivo para a escolha do local para o desenvolvimento do trabalho educacional.

De fato, os registros históricos permitem apurar que os missionários que ali chegaram não foram insensíveis para tal realidade, pois compreenderam que aquele povo precisava do evangelho tanto quanto precisava de amparo social. Essa conclusão foi a que chegou Dias (2009, p. 31) em seu livro A Terra Prometida de Lavras, que narra a história da Universidade Federal de Lavras. O autor identifica clara preocupação social nas iniciativas educacionais dos missionários americanos que atuaram em Lavras nesse período, afirmando que não se "prega fé a estômagos vazios". Segundo o autor, mais do que a pregação da reforma, os missionários trouxeram para Lavras um avanço de conquistas sociais.

\section{Os valores do cristianismo protestante e sua expressão social na educação em Lavras MG}

A partir do levantamento dos dados históricos relativos ao trabalho missionário em Lavras, são apresentadas aqui, pelo menos duas iniciativas que demonstram com clareza o alcance social dos valores educacionais protestantes, ambos os casos para a educação primária de crianças e adultos. No entanto antes de considerar estas informações históricas, torna-se relevante uma objetiva abordagem sobre definições relativas à 
Educação Social na busca de aproximações e conexões com a temática acadêmica que orienta a análise ora desenvolvida.

Quando considerados os delineamentos relativos a Educação Social que são encontrados na obra de Trilla (1996), é possível apresentar três definições para esta área de estudo: a) uma educação que tem como objetivo o desenvolvimento social do indivíduo. Nesse caso o conceito "social" se refere a um objetivo da educação, que seria o desenvolvimento social da pessoa. O critério de abordagem é claramente psicológico; b) uma educação que tem como destinatários os indivíduos que se encontram em risco social. Nesta definição, o conceito nos remete para as questões e os problemas sociais dos indivíduos, portanto, tem se a partir dessa perspectiva um critério mais sociológico de abordagem; c) como uma educação não formal. Nesta última definição, o ponto de ligação são os agentes, que se encontram nos contextos sociais, onde ela é comparada com a educação escolar. Neste caso, o critério de abordagem é fundamentalmente pedagógico, ou seja, há relações com a educação formal, educação não formal, e educação informal.

As definições (b) e (c), se encaixam melhor na abordagem deste trabalho, tendo em vista que os dados históricos nos apresentam um fato ou realidade social, que envolve uma carência e uma exposição da maior parte da parcela da população do país ao risco no terreno social, neste caso com o foco na falta de instrução da sociedade brasileira. Embora seja esse o ponto principal dessa abordagem, não se pode ignorar o fato de que as iniciativas também se enquadram ou se relacionam com os aspectos pedagógicos, tendo em vista os diferentes níveis de instrução que se considera dentro das propostas que esses missionários trouxeram para a sociedade daquele período.

É pavimentada por tais considerações que se que se conduz a apresentação dos dados históricos relacionados às iniciativas que este artigo apresenta como elemento matricial no âmbito do debate sobre a relação dos valores educacionais calvinistas e sua expressão na promoção da Educação Social no Brasil.

\subsection{A Escola Gratuita em Lavras MG}

A primeira iniciativa a ser relatada refere-se à uma experiência educacional que se estabeleceu na última década do século XIX, quando Samuel Gammon iniciou algo inédito na cidade Lavras MG, e que chamou a atenção da imprensa local, que de certo 
modo reconhecia na figura dos missionários uma esperança para o socorro das necessidades daquela comunidade, especialmente no que se refere à educação.

Dos jornais da época reunidos no desenvolvimento desta pesquisa, todos são unânimes em matéria de enaltecer a presença dos missionários na cidade, especialmente por seus projetos educacionais.

Nesse sentido, vale mencionar alguns dos tais como "O Caracter", de propriedade de um tal João Alves Junior, que publicado aos domingos, circulou na cidade até a última década do século XIX, trazendo sempre notas de exaltação quanto aos trabalhos realizados pelos missionários, tendo especialmente na figura de Samuel Gammon o constante alvo de seus elogios, o que demonstra o apreço pela sua atuação na cidade. Em novembro de 1895 passou a denominar-se "Cidade de Lavras".

A edição do referido jornal, em 18 de agosto de 1895 enaltece a figura do missionário Samuel Gammon em razão de sua disposição em oferecer "instrucção primaria gratuita" nas dependências do prédio onde funcionava o Instituto Evangélico. Iniciativa inédita na cidade e que causou certo impacto naquela comunidade:

O Rev Samuel R.Gammon, um norte-americano, offerece aos pobres desta cidade uma escola, onde a par do ensino se-lhes ministrarão licções de moralidade. Não estamos enganados? Pois o que nenhum Lavrense ainda fez, vem fazêl-o um extrangeiro? E com que fim o Rev Samuel R. Gammon abre aos pobres uma escola [grifo meu] - elle não quer votos, elle, que não ama a prebendas e sinecuras, elle, que não se deu siquer o que lhe é devido?

É christão o Rev. Samuel R. Gammon e isto tudo explica [...]

Ao povo só dizemos

"Vê, medita e compara"! (O CARACTER, 1895, p.2)

Como se pode notar, a resposta que o jornalista encontra para justificar a atuação impactante do missionário em oferecer uma "escola para os pobres" está nos seus valores cristãos. Nesse sentido que se propõe nesse trabalho uma discussão sobre o alcance social promovido por tais valores, que claramente se expressaram no passado com uma implicação no socorro de vulneráveis e na promoção da dignidade humana. Este era um dos lemas que norteou o trabalho educacional de Samuel Gammon, o "progresso humano" $"$.

\footnotetext{
4 "Dedicado a glória de Deus e ao progresso humano" - Lema do Instituto Presbiteriano Gammon
} 
Para normatizar este ensino, Samuel Gammon criou um "Regulamento para Eschola Gratuita", tratava-se de um documento com as exigências para ser matriculado e frequentar as aulas que eram oferecidas.

\begin{abstract}
"Um folheto de 1895 divulgava o "Regulamento da Eschola Gratuita" o que demonstrava a preocupação com a educação de todos nas matérias do Curso Primário:

... abriu-se num prédio no Largo de Sant'Anna uma escola de instrução gratuita. 1- os paes têm de fornecer os livros, cadernos, penas, lápis, pedras, etc. 2 - Os alunos devem vir sempre asseiados. 3 - é de primeira necessidade e uma condição indispensável que os alunos assistam com regularidade. Flatoando nisto perderão o privilégio das aulas, visto ser impossível o aluno adiantar-se nos seus estudos sem regularidade na assistência, Samuel R. Gammon, Directo, Lavras, agosto de 1895" (BEZERRA, 2016. p.147).
\end{abstract}

Certamente a "escola de instrução gratuita" de Samuel Gammon foi o meio que viabilizou a muitas das crianças carentes e marginalizadas que viviam em "maior pobreza nos arredores da cidade" (GAMMON, p. 58), a terem seu primeiro contato com a instrução, através de um curso primário. Considerando os dados históricos levantados e os dados bibliográficos apresentados, temos a Educação Social expressa conforme a descrição sociológica de Trilla (1996): uma educação que tem como destinatários os indivíduos que se encontram em risco social. Nesta definição, o conceito nos remete para as questões e os problemas sociais dos indivíduos e da comunidade lavrense.

\title{
5.2 O Ensino Profissionalizante e o Fundo Hunnicutti
}

Também em considerações às realidades sociais locais, foi que Samuel Gammon se preocupou em oferecer um ensino profissionalizante, para melhorar as condições e possibilidades da juventude lavrense. Nesse sentido, a imprensa local também reconhece a carência e enaltece a sensibilidade e iniciativa do missionário.

Um outro veículo de imprensa enaltece esse outro projeto de Samuel Gammon. Nas páginas de "O Municipal”, um jornal de propriedade de José de Mesquita, na edição $\mathrm{n}^{\circ}$ 4, de 9 de fevereiro de 1902, junto a um desabafo pela frustração devido precariedade local em relação a educação profissional, a redação do periódico, enaltece o que era ainda um projeto de Gammon: 


\section{Um projecto util}

Entre nós succede em geral que os meninos, depois de estudarem as primeiras letras, vão para casa de seus paes, onde se empregam quasi sempre em serviços improductivos, quando não passam os dias na mais deploravel ociosidade. Exceptuados os que seguem carreira scientifica e alguns dos que se collocam no commercio ou em repartições publicas, quasi todos os outros, póde-se dizer, crescem numa lastimável ignorancia dos conhecimentos mais rudimentares, e já homens feitos, são de todos inexperientes da vida ou então só conhecem do mundo os vicios que nelle contranbhiram. Ora, em taes condições, difficilmente terão amor ao trabalho ou poderão prezar a probidade, e dahi não virem a ser bons chefes de familia, que pelo menos façam dos filhos cidadãos laboriosos, honestos e dotados de alguma educação [...]. É em parte causador disso o poder publico que, sem um bem pensado programma administrativo, tem não poucas vezes maltratado os dinheiros do Estado em obras adiaveis, sinão desnecessarias, quando melhor poderia aplical-os, por exemplo, no estabelecimento de institutos profissionaes, onde os nossos moços aprenderiam desde cedo a trabalhar em alguma arte ou officio que os tornassem aptos para a lucta da vida.

Do exposto se vê quanto é util para nós a fundação de um institucto profissional em que se ensine aos nossos jovens uma arte ou officio, cuja aprendizagem é sempre de incontestavel vantagem para ganhar a vida, principalmente hoje que ella se acha tão difficil e dispendiosa. Para a sociedade lavrense haverá, pois, motivo de regosijo em saber que, segundo nos consta, vae ser criado aqui um collegio para meninos, onde estes tambem poderão aprender alguma arte ou officio. Abençõe Deus esse projecto util, para cuja realização está trabalhando o illustre ministro evangelico Samuel Gammon, que pretende tornal-o effectivo daqui a um anno, quando regressar de sua viagem dos Estados Unidos. É de esperar que o povo lavrense preste todos seus concurso á bem o fazeja idéa do sr.Gammon, cujo nobre caracter e fina educação nós todos muito bem conhecemos [grifo meu] (O MUNICIPAL, 1902, p.4)

Nesta matéria encontramos um desabafo acompanhado de um fio de esperança depositado na iniciativa de Gammon, o descaso do estado para com as necessidades educacionais locais fazia com que o cidadão lavrense encontrasse nas iniciativas dos missionários protestantes que ali se estabeleceram, uma esperança de socorro às condições precárias de instrução a que estavam legados os cidadãos do interior do Estado de Minas Gerais.

É importante a essa altura, lembrarmos que dentro das definições de Educação Social que temos considerado percebemos que os projetos respondiam uma carência social daquele lugar interiorano e visava preparar indivíduos para a sociedade. Mais tarde o projeto acabou se tornando muito maior do que se imaginava, principalmente com a fundação da Escola Agrícola em 1908. 
É notório como os mais variados órgãos de informação local enaltecem juntos as iniciativas educacionais dos missionários protestantes. Os mais diversos veículos reconhecem que de fato, os missionários vieram verdadeiramente socorrer a cidade no que tange a sua carência educacional, é caso do jornal "Vida Escolar" de 1 junho de 1908, editado pelo educador Firmino Costa, em que é possível encontrar mais indicativas em relação ao modo como o trabalho educacional dos missionários era considerado em sua relevância naquela cidade interiorana.

Do Instituto Evangelico podemos dizer que não só por si mesmo, como tambem indirectamente, pela sua acção animadora e pelas rivalidades que despertou, foi o principal factor do desenvolvimento deste logar [grifo meu], hoje um centro invejável de meios de educação. Os novos methodos de ensino alli adoptados, uma comprehensão melhor da vida alli observada, uma direcção consentânea com os modernos principios de pedagogia, teem tornado o Instituto um estabelecimento recommendavel a todos os chefes de familia.

É de justiça assignalar que o Instituto marcou uma nova phase para a instrucção em Lavras. As tentativas anteriormente feitas para a creação de collegios nesta cidade evidenciam sem duvida o amor e o interesse de nossos conterraneos á causa da instrucção, porêm ellas nunca chegaram a resultados seguros e duradouros

Quanto de competência, de esforço e de perseverança tem custado a seu digno director essa carreira brilhante do Instituto, não será fácil avaliar! Hoje, volvidos quinze anos, a nossa sociedade culta já reconhece o enorme beneficio, que nos trouxe de sua patria esse norte-americano, cavalheiro distinctissimo e emerito educador, o sr.dr. Samuel Gammon, a quem deve Lavras essa importante casa de educação, que é o Instituto Evangelico, por elle dirigido desde o principio (VIDA ESCOLAR, 1908, p.3).

Neste texto de Firmino Costa já é possível acessar a uma descrição mais robusta do Instituto Evangélico com suas diferentes escolas. Deve-se lembrar, que o Instituto Evangélico, diferentemente da Escola Gratuita que foi mencionada anteriormente, era uma instituição particular, e apenas famílias com recursos poderiam encaminhar seus filhos para a instituição, e é nesse sentido que surgiu a segunda iniciativa que precisa ser considerada em uma discussão sobre o alcance social desta atuação missionária educacional baseada em valores do cristianismo reformado, e que conforme pontuado, se apresentou como elemento decisivo neste contexto de desenvolvimento educacional no interior do Estado de Minas Gerais, e neste caso, a segunda iniciativa a que me refiro é o Fundo Hunnicutt.

Para compreender melhor a origem deste fundo de recursos para estudantes e famílias carentes, torna-se salutar breves considerações sobre o personagem histórico que 
lhe emprestou seu nome, Benjamin Harris Hunnicutt (1886-1962). Nascido em 1886, em um "lugarejo" no interior do Estado da Geórgia, o recém-formado agrônomo chegou ao Brasil em 1907, com apenas 21 anos de idade, e com a responsabilidade de instalar em Lavras uma Escola Agrícola a pedido do idealizador Samuel Gammon. Não somente por sua contribuição na fundação da Escola de Agronomia de Lavras (EAL), Hunnicutt se tornou uma referência na pecuária e agricultura por introduzir no Brasil suínos da raça Duroc Jersey e por dignificar a cultura agrícola do milho.

Benjamin Hunnicutt dirigiu a Escola Agrícola por mais de 20 anos. No início da década de 30 foi transferido para São Paulo, onde passou a atuar no Mackenzie College, do qual foi presidente até 1951, sendo seu mandato o mais longo de todos os dirigentes máximos da instituição.

É possível encontrar ruas com seu nome em São Paulo, Lavras, Guarulhos e Campos do Jordão. Também deu nome a um dos prédios que compõem o campus da Universidade Presbiteriana Mackenzie, em São Paulo. Dentre as homenagens se destaca a outorga pelo Presidente Getúlio Vargas, da comenda da Ordem Nacional do Cruzeiro do Sul, maior condecoração dada a um estrangeiro.

Preocupado com estudantes que não possuíam recursos para estudar no Instituto Evangélico, Benjamim Hunnicutt, no dia 2 de dezembro de 1921 enviou uma carta à Mesa de Curadores do Instituto Evangélico expondo a sua intenção de criar, em parceria com o Instituto, um meio para viabilizar empréstimos à estudantes carentes.

O projeto seria denominado Fundo Hunnicutt em homenagem a familiares que haviam doado os valores. Ainda no mês de março de 1922 seriam entregues um conto de réis e mais notas promissórias de 300 mil réis para empréstimos já efetuados. Alguns pontos do projeto chamam muita atenção, por exemplo:

a) Todo o valor ficaria nas Mãos dos Curadores do Instituto Evangélico;

b) Todo o fundo deveria ser usado exclusivamente para empréstimos;

c) Havia uma ficha de preenchimento e assim lançamento da candidatura;

d) O pagamento seria feito o mais breve possível, mas somente após a graduação e caso feito no primeiro ano após a graduação seria completamente isento de juros;

e) Não era necessário fiador, os alunos apenas assinavam uma nota promissória;

f) Era dada uma preferência para estudantes da área agrícola; 
g) Foi nomeado um comitê pela Mesa de Curadores no intuito de avaliar as candidaturas;

h) O fundo poderia receber contribuições de outras fontes.

As condições denotam o aspecto de interesse social do projeto em viabilizar o acesso de alunos carentes ao ensino profissionalizante. Já nos seus primeiros anos, alunos de vária partes do país foram contemplados com este benefício.

\subsection{Educação Social em São Paulo}

Mencionada a trajetória de Hunnicutt, que foi igualmente marcante na história do Instituto Presbiteriano Mackenzie, torna-se relevante demonstrar como os valores cristãos reformados também foram decisivos em uma atuação de relevância social na área da Educação que também foi documentada em São Paulo.

Os pesquisadores da história do Instituto Presbiteriano Mackenzie também encontram nas origens da instituição, que aconteceu nas últimas décadas do século XIX, elementos diretamente ligados à uma atuação voltada para atender demandas relacionadas à falta de instrução do povo.

Na obra Mackenzie de Benedicto Navaez Garcez, ao tratar sobre a origem do Instituto Presbiteriano Mackenzie, o autor relaciona sua fundação à um projeto de Alfabetização de adultos iniciado pelo missionário George Whitehill Chamberlain (18391902), que vindo dos Estados Unidos, assim como Samuel Gammon, foi responsável por orientar a obra educacional leiga da igreja que se iniciava em São Paulo, e um dos projetos que desenvolveu foi a alfabetização de adultos, que acontecia na rua Libero Badaró, no centro da cidade de São Paulo.

Segundo Garcez (1970 p. 10), "larga campanha se fêz em favor da alfabetização de adultos [...]". É evidente que estes primeiros esforços dos missionários se relacionavam inicialmente com o atendimento daqueles que os procuravam, que naquele contexto eram categorizados como "simpatizantes" da religião protestante, uma vez que no país havia grande hegemonia católica. Garcez (1970, p.11) afirma que por esse projeto foi travada uma "verdadeira guerra sem quartel", sendo que muitos adultos que foram alvos deste projeto dos missionários "aprenderam a ler usando como cartilha as páginas da própria bíblia". O mesmo autor relaciona a alfabetização de adultos como uma tradição do 
Mackenzie, ligado a suas origens: "a ideia de se organizar uma escola ainda nos tempos do Império, nasceu evidentemente do antigo costume de se alfabetizarem os adultos [...]”.

Quando o Mackenzie, em 1935, em parceria com o governo do Estado de São Paulo, estabeleceu diversos pontos de alfabetização de adultos, Garcez (1970 p.196) afirmou:

[...] o Centro Acadêmico Horácio Lane resolveu reencetar a velha tradição Mackenzista de alfabetização de adultos". Em relação a este assunto ele afirma que o aparecimento da Escola Americana tem relação direta ao esfoço na alfabetização de adultos: "quanto à alfabetização de adultos que, na realidade foi o motivo principal do aparecimento da 'escolinha da Senhora Chamberlain', até hoje o Centro Acadêmico Horácio Lanem, associação estudantil da Escola Engenharia Mackenzie, mantém a tradição secular, sustentando três escolas noturnas gratuitas para alfabetizar adultos. Nesses cursos milhares de pessoas aprenderam a ler e escrever, tornando-se cidadãos úteis ao Brasil (GARCEZ, 1970, p.46).

Marcel Mendes (2016) é outro pesquisador que também aponta um caráter diferenciado da atuação educacional protestantes no que se refere ao atendimento de demandas sociais da época. De acordo com o autor, logo que Chamberlain e sua esposa Mary Ann chegaram em São Paulo "ocorreu-lhes a ideia de abria as portas de sua residência nos Campos Elíseos para ministrar lições de alfabetização a crianças não inseridas nas elites paulistanas".

Para além de oportunizar a alfabetização através de iniciativas que ofereceram instrução gratuita, assim como a sua instituição análoga em Minas, o Mackenzie sempre se preocupou em garantir a oportunidade de estudos à pessoas carentes através dos seus sempre presentes programa de Bolsas de Estudo, hoje ainda presente na instituição, por meio do departamento de filantropia.

Do ponto de vista histórico, é importante a reprodução de uma observação feita em 1970 por Benedicto Garcez:

Uma das características do Mackenzie tem sido a concessão de bolsas de estudo a estudantes sem recusos. Esta praxe vem sendo mantida através dos 100 anos de sua existência. Milhares de profissionais, engenheiros, arquitetos, advogados, químicos, contadores, comerciantes, industriais, funcionários públicos, etc, estudaram no Mackenzie com bolsas escolares. O lado mais nobre da questão é que ninguém fica sabendo dessa condição, nem os colegas e nem os professores pois, tanto o estudante que paga regularmente sua anuidade 
como o bolsista, têm os mesmos direitos e obrigações (GARCEZ, 1970, P.46).

Esta atuação relevante do Mackenzie em São Paulo no que se refere a Educação Social, é apresentada neste artigo meramente como uma ilustração prática que evidencia o fato de que os valores inerentes ao protestantismo, não são condicionados a contextos sociais e geográficos específicos, mas são inerentes ao movimento protestante em si, como elemento constituinte de suas características e que impulsiona um trabalho educativo que se encaixa exatamente no que atualmente se categoriza academicamente como Educação Social.

\section{Considerações Finais}

Conforme pontua o pesquisador da área de Educação Social, João Clemente de Souza Neto (SOUZA NETO apud REZENDE, 2017), a investigação histórica do trabalho dos educadores protestantes na cidade de Lavras é mais uma oportunidade de acesso a relatos de experiências fragmentadas que se dão em campos e contextos específicos e localizados, conduzidos por diferentes grupos, é exatamente assim que Souza Neto (2010, p.29) caracteriza “o contexto de ação do educador social”, "pela ação de grupos ideológicos e organizados, disputas políticas e religiosas, experiências de injustiça, perdas e frustrações" e que "exige dele capacidade de intervir pedagogicamente na realidade e de mediar relações, para abrir perspectivas de desenvolvimento individual e social”.

Ressalta-se portanto, o que foi pontuado no início da presente abordagem, de que embora a Educação Social, conforme pontua Gadotti (2013), seja uma novidade como assunto acadêmico, é necessário que percebamos algumas de suas características presentes na atuação destes missionários calvinistas no século XIX e início do século XX, e nesse sentido, o referido autor nos chama atenção para o fato de que como prática, não é possível identificar quando ela começou à estar presente no país, pois o mesmo autor, caminha com Paulo Freire (2005), na percepção de que toda educação é social, "pois todo processo educativo é contraditório e os educadores e educadoras, podem incidir sobre essas contradições, acirrando-as no seu interior e transformando realidades históricas.”

Os missionários norte-americanos que chegaram a Lavras nesse período não ignoraram os pobres e marginalizados, e de fato, os seus valores cristãos não permitiriam tamanha contradição entre teoria e prática. “O educador transmite normas e valores, mas 
também atua no sentido de preparar para superar conflitos, sofrimentos e tensões" (SOUZA NETO, 2010, p. 29).

Neste sentido, precisamos lembrar, conforme afirma Gaddotti (2013, p.3), que na pedagogia do oprimido de Paulo Freire, não são apenas os oprimidos que ocupam seu pensamento, mas ele está pensando também nos não-oprimidos que com os oprimidos “sofrem”, mas sobretudo "com eles lutam". "Penso que os educadores sociais são também aqueles que, mesmo não sendo, necessariamente, oprimidos, lutam ao lado deles".

É preciso que se perceba que a herança educacional calvinista, representada por várias instituições no Brasil e especialmente na América do Norte e Europa, possui um alcance social muito significativo e amplo. Nisso se constitui o objetivo desse trabalho, que se apresenta mais como uma parte provocativa de discussão acadêmica, do que elemento exaustivo de abordagem. As iniciativas dos missionários em Lavras revelam significativo alcance social de suas atividades possibilitando que estudantes carentes tivessem acesso à educação em diferentes níveis, do primário, até o superior, em um período histórico em que o país apresentava graves deficiências na disponibilização da instrução para população, especialmente aos mais carentes.

Vários trabalhos acadêmicos têm apontado nos últimos anos os aspectos de pioneirismo relacionados ao trabalho educacional dos presbiterianos na cidade interiorana de Lavras MG, e pelo que parece, a presente investigação exposta neste artigo, mais um ponto vem incidir, a saber, o pioneirismo destes missionários em iniciativas de viabilização da instrução em diferentes níveis para crianças, jovens, e adultos em situação de vulnerabilidade social, conforme os próprios jornais da época apontaram.

A investigação apresentada neste artigo não tem o propósito de ser somente um registro de fatos passados, mas se propõe como um objeto de análise que oportunize um aproveitamento de elementos educacionais que possam favorecer o desenvolvimento de políticas para a Educação Social. O pioneirismo dos protestantes em sua pedagogia social no interior do estado de Minas Gerais se torna útil do ponto de vista histórico quando cumpre o papel de contribuinte no desenvolvimento de uma proposta para a Educação no século XXI, que seja relevante no aspecto geoeconômico e eficiente no aspecto pedagógico inclusivo. É assim que o modelo de educação desenvolvido em Lavras tem sido interpretado por vários autores ${ }^{5}$, como elemento revelador de uma preocupação em

\footnotetext{
${ }^{5}$ MEIRA (2009); ROSSI (2010); PEREIRA (2014); OLIVEIRA (2014); REZENDE (2017);
} 
oferecer respostas aos anseios e expectativas sociais do seu tempo e espaço. Samuel Gammon e seus pares acreditavam em uma educação que pudesse mudar realidades sociais, contribuindo para o progresso da sociedade.

\section{Referências Bibliográficas}

CRESPIN, Jean. A Tragédia da Guanabara: a história dos primeiros mártires do cristianismo no Brasil. São Paulo: Cultura Cristã, 2007.

DAGAMA, J. F. A Brief Account of the Great Empire of Brazil our Mission Work and its presente needs. Jacksonville: Illinois, 1882.

DIAS, João Castanho. A Terra Prometida de Lavras. São Paulo: Editora Barleus, 2009.

DURKHEIM, Émile. As regras do método sociológico. 17 ed. São Paulo: Companhia Editora Nacional, 2002.

FERREIRA, Wilson Castro. Calvino: Vida, Influência e Teologia. Campinas SP: LPC, 1990.

FREIRE, Paulo. Pedagogia do Oprimido. Rio de Janeiro: Paz e Terra, 2005.

GADOTTI, Moacir. Educação Popular, Educação Social, Educação Comunitária: conceitos e práticas diversas, cimentadas por uma causa comum. Scielo n 4 vl 2, 2013. Disponível em: http://www.proceedings.scielo.br/pdf/cips/n4v2/13.pdf

GAMMON, Clara. Assim Brilha a Luz: A vida de Samuel Rhea Gammon. São Paulo: Editora Cultura Cristã, 2003.

GAMMON, Samuel R. The Evangelical invasion of Brazil; Or, a half century of evangelical mission in the land of the southern cross. $2^{\mathrm{a}}$ ed. Memphis: General Books, 2010;

GARCEZ, Benedicto. Mackenzie. São Paulo: Casa Editora Presbiteriana, 1970;

GONZÁLEZ, Justo L. História Ilustrada do Cristianismo: a era dos reformadores até a era inconclusa. Vol 2. São Paulo: Vida Nova, 2011.

GRUPO Escolar. Vida Escolar. Lavras, ano I, n 2, 15 de mai. 1907

HACK, Osvaldo Henrique. Protestantismo e Educação Brasileira. São Paulo: Cultura Cristã, 2000.

HUNNICUTT, Benjamim Harris. Origem da Escola de Agronomia de Lavras. O Agrário. Lavras MG, ano XII, n. 52, set. 1958

HUNNICUTT, Benjamim Harris. Correspondência pessoal à Mesa de Curadores do Instituto Evangélico. Lavras, 2 dez. 1921. Pasta de arquivo: Correspondências. Acervo Pró-Memória

INSTITUTO EVANGÉLICO DE LAVRAS. Prospecto do Instituto Evangélico. Lavras: Typografia do Ginásio de Lavras, 1908.

INSTITUTO Evangélico. Vida Escolar. Lavras, ano II, n²3, 1 de jun. 1908;

INSTRUCÇÃO Primaria Gratuita . O Caracter. Lavras, p.2, 18 de ago. 1895. 
JÚNIOR, Lincoln Etchebèhére et. al. . Educação e Filantropia na Cidade de São Paulo, no final do século XIX e primeiras décadas do século XX; um estudo da obra do conde José Vicente de Azevedo no Bairro do Ipiranga. História da Educação, ASPHE/FaE/UFPel, Pelotas, n. 22, p. 155-181, Maio/Ago 2007

KOSELLECK, Reinhart. Futuro Passado: contribuição à semântica dos tempos históricos. Rio de Janeiro: Contraponto, 2006.

LÉRY, Jean. Viágem a Terra do Brasil. Rio de Janeiro: Biblioteca do Exército - Editora, 1961.

MEIRA, José Normando Gonçalves. Ciência e Prática: Ensino Agrícola na Educação Presbiteriana em Minas Gerais (1908-1938). 2009. 222 f. Tese (Doutorado EHPS História da Educação) - Pontifícia Universidade Católica, São Paulo, 2009.

MENDES, Marcel. Tempos de Transição: a nacionalização do Mackenzie e sua vinculação eclesiástica. São Paulo: Editora Mackenzie, 2016.

OLIVEIRA, Guilherme Ferreira. Para a glória de Deus e para o progresso dos homens: pensamento missionário norte americano e representações de Brasil a partir de The evangelical Invasion (1910), de Samuel Rhea Gammon. 2014. 198f. Dissertação (Programa de Pós-graduação em História) - Universidade Federal de São João Del-Rei, São João Del-Rei MG;

PEREIRA, Jardel Costa. O Moderno no progresso de uma cultura urbana, escolar e religiosa e a educação secundária do Instituto Presbiteriano Gammon (1892-1842). 2014. 190 f. Tese (Programa de Pós-graduação em Educação Escolar - Faculdade de Ciências e Letras) Universidade Estadual de São Paulo, Araraquara SP;

QUINTANA, J. Ma . Antecedentes Históricos de la Educación Social. In: PETRUS, A. (Coord.) Pedagogía Social. Barcelona, Ariel. 1997 p.71-73

REZENDE, Lucas Pereira. O Ensino de Laticínios nos Primórdios da Universidade Federal de Lavras (1908-1938). 2017. 165 f. Dissertação (Mestrado EAHC - Educação, Arte e História da Cultura) - Universidade Presbiteriana Mackenzie, São Paulo, 2017.

RIBEIRO, Domingos. Origens do Evangelismo Brasileiro. Rio de Janeiro: Est. Graph. Appolo, 1937.

RIBEIRO, João. História do Brasil. 9a ed. São Paulo: Livraria Francisco Alves, 1920.

ROSSI, Michele Pereira da Silva. Dedicado à Glória de Deus e ao progresso humano: a gênese protestante da Universidade Federal de Lavras - UFLA (Lavras, 1892-1938). 2010. 285f. Tese (História e Historiografia da Educação) - Universidade Federal de Uberlândia, Uberlândia MG.

SALVADOR, Frei Vicente do. História do Brasil (1500-1627). São Paulo: Edições Melhoramentos, 1975.

SOUZA NETO, João Clemente. Pedagogia Social: a formação do educador social e seu campo de atuação. Cadernos de Pesquisa em Educação PPGF /UFES. Vitória, v. 16, n. 32, p. 29-64. Jul/Dez 2010. Disponível em https://periodicos.ufes.br/educacao/issue/view/336. Acesso jan. 2018.

TRILLA, Jaume. La educación fuera de la escuela. Barcelona: Ariel, 1996

UM PROJECTO Util. O Municipal. Lavras, nº4, 9 de fev. 1902. 


\section{Edurañâ,Escolar Sociedace}

VILELA, Marcio Salviano. A Formação Histórica dos Campos de Santa'Ana das Lavras do Funil. Lavras: Editora Indi, 2007 